\title{
Psychometric properties and validation of the Italian version of the Family Assessment Measure Third Edition - Short Version - in a nonclinical
} sample

\author{
This article was published in the following Dove Press journal: \\ Psychology Research and Behavior Management \\ 28 February 2017 \\ Number of times this article has been viewed
}

\author{
Monica Pellerone' \\ Tiziana Ramaci' \\ Santa Parrello ${ }^{2}$ \\ Paola Guariglia' \\ Flavio Giaimo' \\ 'Faculty of Human and Social Sciences, \\ "Kore" University of Enna, Enna, \\ ${ }^{2}$ Department of Humanities Studies, \\ "Federico II" University of Naples, \\ Napoli, Italy
}

Background: Family functioning plays an important role in developing and maintaining dysfunctional behaviors, especially during adolescence. The lack of indicators of family functioning, as determinants of personal and interpersonal problems, represents an obstacle to the activities aimed at developing preventive and intervention strategies. The Process Model of Family Functioning provides a conceptual framework organizing and integrating various concepts into a comprehensive family assessment; this model underlines that through the process of task accomplishment, each family meets objectives central to its life as a group. The Family Assessment Measure Third Edition (FAM III), based on the Process Model of Family Functioning, is among the most frequently used self-report instruments to measure family functioning. Materials and methods: The present study aimed to evaluate the psychometric properties of the Italian version of the Family Assessment Measure Third Edition - Short Version (Brief FAMIII). It consists of three modules: General Scale, which evaluates the family as a system; Dyadic Relationships Scale, which examines how each family member perceives his/her relationship with another member; and Self-Rating Scale, which indicates how each family member is perceived within the nucleus. The developed Brief FAM-III together with the Family Assessment Device were administered to 484 subjects, members of 162 Italian families, formed of 162 fathers aged between 35 and 73 years; 162 mothers aged between 34 and 69 years; and 160 children aged between 12 and 35 years. Correlation, paired-sample $t$-test, and reliability analyses were carried out. Results: General item analysis shows good indices of reliability with Cronbach's $\alpha$ coefficients equal to 0.96. The Brief FAM-III has satisfactory internal consistency, with Cronbach's $\alpha$ equal to 0.90 for General Scale, 0.94 for Dyadic Relationships Scale, and 0.88 for the Self-Rating Scale. Conclusion: The Brief FAM-III can be a psychometrically reliable and valid measure for the assessment of family strengths and weaknesses within Italian contexts. The instrument can be used to obtain an overall idea of family functioning, for the purposes of preliminary screening, and for monitoring family functioning over time or during treatment.

Keywords: family assessment, psychometric properties, Italian validation, family strengths, family weaknesses

\section{Introduction}

Family is an interpersonal system, that evolves through a continuous process of identity construction, characterized by the constant search for balance between tendencies to stability and potential changes, ${ }^{1}$ defined as the family life cycle. ${ }^{2,3}$ This developmental cycle is characterized by a sequence of different phases that mark its course: the young couple, the young adult who is confronted with one's new family and one's
Correspondence: Monica Pellerone Faculty of Human and Social Sciences, "Kore" University of Enna, Via Cittadella Universitaria, snc, Enna (EN), Sicily 94100 , Italy

Tel +39329432 43II

Email monica.pellerone@unikore.it 
birth family, the nucleus with young kids, the family with adolescent children, the "springboard" family for children, and the family in old age. ${ }^{4}$

The psychosocial approach ${ }^{5,6}$ describes identity development as a process that involves the completion of a series of developmental tasks; ${ }^{7,8}$ similarly, in the family life cycle, each step is characterized by specific tasks, leading to changes in the relationship between spouses, in parent-child relationships, and in those with the birth family, and whose solution allows the transition to the next step and the acquisition of a family functioning. ${ }^{4}$

Family plays a critical role in the development of individual characteristics, highlighting the interdependence between the individual life and the family life cycle. It affects the growth of every member and the normal operation process of the social system..$^{9-11}$ Therefore, the family function is restricted by the family characteristics and the social context, but it also depends on numerous internal factors such as communication, beliefs, cohesion, adaptability, structure, relational quality, parenting style, task accomplishment, competence, conflict, and the problem-solving ability of family members. ${ }^{12-14}$

In the past, the definition of family functioning presented many challenges such as the structuring of different theoretical models and the presence of numerous assessment tools. Nowadays, the researchers of family functioning have two main theories: the first - result oriented, which defines family functioning based on the specific features of the family and evaluates the individual characteristics of members and their interactions; the second - process oriented, which describes family function based on the tasks families need to complete and extends the focus on the influence of past events on future behaviors. ${ }^{15}$

As representatives of result-oriented family function, Olson et $\mathrm{al}^{16}$ identified three dimensions that contribute to the overcoming of a stressful event: 1) cohesion, which is the distance or proximity from the psychological, cognitive, and affective point of view; 2) adaptability, or the ability to change the family structure, based on events that occur during the life cycle; and 3) communication, which is a mode that family members use to express their needs and feelings. ${ }^{16}$

As a representative of process-oriented function, the McMaster family functioning model, proposed by Epstein, ${ }^{9}$ assumes that the basic function of family is to provide appropriate environmental conditions so that members will develop physically, psychologically, and socially; to acquire the basic function, the family system must complete a series of tasks, such as basic, developmental, and crisis. ${ }^{15}$

In comparison to this theory, the Process Model of Family Functioning, proposed by Skinner, ${ }^{17}$ emphasizes the interaction between individual and the overall relationship. This theory uses the McMaster family model to form a more systematic and clear structure of family functioning; in particular, the author defines family as a dynamic operation system and examines family function from seven dimensions: completion of task, role, communication, emotional expression, involvement, behavior and values, and rules. The interaction among seven dimensions leads a family to fulfill its function and adapt to changes between the various tasks.

The literature cited earlier underlines how the assessment of family functioning presented many challenges; for instance, the emphasis placed on examining the individual characteristics of members or the extent of focus on past events versus ongoing family behavior. These challenges stimulated the theorization of new assessment models in order to understand, measure, and treat the problematic families; in fact, literature has amply demonstrated that family functioning plays an important role in developing and maintaining dysfunctional behaviors, especially in adolescence. ${ }^{12,15}$ The lack of relevant indicators of family functioning as key determinants of personal and interpersonal problems is a serious impediment to developing preventive and treatment strategies. Furthermore, parallel to the increasing interest for family therapy and the role played by family in both health and psychiatric conditions, there is increased need for tools capable of assessing family functioning both in clinical and research settings. This need represents an important starting point to work with children and their families in order to measure their strengths and weaknesses and project family therapy. ${ }^{18}$

\section{The Process Model of Family Functioning}

The Process Model of Family Functioning provides a conceptual framework that organizes and integrates various concepts into a comprehensive family assessment. ${ }^{19}$ This model underlines that through the process of Task Accomplishment, each family meets objectives central to its life as a group; this process includes the following tasks: problem identification, exploration of possible alternative solutions, implementation of selected approaches, and evaluation of effects. Furthermore, the achieved Task Accomplishment involves differentiation roles within family, or Role Performance, which requires three operations: the allocation of specified activities to each member, the agreement of family members to assume the assigned roles, and the actual enactment of prescribed behaviors. Effective and functional Communication is essential to acquire the Role Performance so that the message received is the same as the message intended by each member. An important element of the communication process is the Affective Expression, 
which includes the content, intensity, and timing of the feeling involved. The type of Affective Involvement of family members could facilitate or limit the Task Accomplishment because it represents the capacity to meet the emotional and security needs of family members, and as the family should be able to both maintain its autonomy and adapt to possible changes required by the tasks, the dimension of Control represents another important process by which family members influence each other. Finally, the selection of family tasks relies heavily on the Values and Norms of individual members, which are developed, in large part, from internalized parental rules, experiences of the birth family, nuclear family history, and cultural influences.

The Process Model of Family Functioning provides a conceptual framework for conducting family assessments, which Skinner et $\mathrm{al}^{20}$ attempt to operationalize through the structuring of the Family Assessment Measure instrument. In particular, the Family Assessment Measure Third Edition (FAM-III) developed by Skinner et al, ${ }^{21}$ approximately 10 years later, is among the most frequently used self-report instruments to measure the family functioning. Based on the Process Model of Family Functioning, it emphasizes family dynamics and measures the strengths and weaknesses inherent in a family's functioning. The theoretical model underlines that each member perceives the level of interaction differently and that relationships within the family can change along with an individual's perception of their own functioning.

\section{Studies conducted with FAM-III and Brief FAM-III}

The FAM-III has been used with many different types of clinical samples, such as families of children with cystic fibrosis or those with developmentally disabled or mentally handicapped children, ${ }^{22,23}$ but few studies have been conducted using FAM scales to evaluate family functioning in nonclinical samples.

Furthermore, several studies have evaluated and correlated the FAM-III with other measures of family functioning in nonclinical samples, such as the Family Adaptability and Cohesion Evaluation Scale (FACES), ${ }^{16}$ the Family Assessment Devise (FAD) ${ }^{24}$ and the Family Environment Scale (FES). ${ }^{25}$ On the whole, the FAM-III was found to have high and significant correlations with these measures, providing support that the FAM is measuring family functioning. In particular, these studies showed that all FAM scales correlated with the dimensions of cohesion, idealization, and expressiveness measured by FACES, ${ }^{26}$ with cohesion and conflict measured by FES, and with all dimensions of FAD. ${ }^{27}$ In terms of weakness, research showed that the validity of the FAM is satisfactory in most studies; the reliability estimates for General and Dyadic Scales are very good, although reliability for Self-Rating Scale is sufficient. ${ }^{26,27}$

To our knowledge, there are no studies of validation on the Brief FAM-III in non-English speaking contexts; and there are few studies on the FAM-III, which presently is available in English, French, Spanish, and Portuguese. In the Italian context, only two studies that have attempted to validate the entire version of the FAM. In particular, Delvecchio et $\mathrm{al}^{28}$ assessed the relationship between expressed emotion and family functioning in a sample of 381 nonclinical parents of adolescents and showed that the parents who expressed high emotion had higher family nonadaptive functioning. Recently Laghezza et $\mathrm{al}^{29}$ have conducted another study in a nonclinical sample of Italian families using only the General Scale of FAM-III. This study, conducted with 1,572 adults, showed good levels of internal consistency for all the subscales, except for the Task Accomplishment that showed poor internal consistency. These two studies show that the Italian version of the FAM-III will be useful and appropriate for the Italian context and will be adequate for assessing parents' perceptions of family functioning and detecting family changes related to different stages of children's development.

Although the FAM-III is one of the most used self-reports to measure family functioning, it was criticized for not being easy to use and for being too long and tiring for individuals in clinical groups. Recently, to overcome these limitations, some researchers have used the short version of the FAM-III (Brief FAM-III), which has demonstrated acceptable levels of reliability, validity, and internal consistency and higher levels of comprehension than the FAM-III. ${ }^{19}$

In fact, the Brief FAM-III, similarly to the FAM-III, is ideal for monitoring family functioning over time or during the course of treatment. Furthermore, the short version can be used to obtain an overall idea of family functioning when there is limited time available with family members and for the purposes of preliminary screening. In particular, a study conducted by Skinner et $\mathrm{a}^{22}$ to assess the ability of the Brief FAM-III to distinguish between the clinical and nonclinical groups showed that all scales (General, Self-Rating, and Dyadic Relationships) had significant discriminatory power. In detail, the mean scores for the nonclinical group were lower than those of the clinical group $(p<0.01)$. Furthermore, correlation analysis between Brief FAM-III and FAM-III total scores showed high level of correlations $(p<0.01)$ for the General ( $r=0.96)$, Self $(r=0.94)$, and Dyadic Scales $(r=0.97)$.

Due to the abovementioned reasons and the lack of any Italian study, the present research aimed to examine the 
psychometric properties of the Italian Version Brief FAM-III, which is a measure of individual family members' perceptions of their nucleus. The original version of Brief FAM-III was translated into Italian, and this involved forward translation, synthesis of the translation, and back translation; this was commissioned by the Multi Health System - Psychological Assessments and Services - and carried out by the researchers at "Kore" University of Enna.

\section{Materials and methods Measures}

The group of participants completed the Brief FAM-III and the FAD.

The Brief FAM-III represents the short version of the Family Assessment Measure Third Edition; the instrument consists of three modules:

1. The Brief General Scale, consisting of 14 items, examines overall family health (a simple item is: "We tell each other about things that brother us");

2. The Brief Dyadic Relationships Scale, with 14 items, examines how a family member views his or her relationship with another member (a simple item is: "This person accepts what I expect of him/her in the family");

3. The Brief Self-Rating Scale consists of 14 items and allows each person to rate his or her own functioning within the family (a simple item is: "My family knows what I mean when I say something"). ${ }^{22}$

The Brief FAM-III may be completed by children 10 years or older or by adults with a grade 5 reading level; older family members who have difficulty reading, may need someone to help them to interpret some questions; the short version of each scale generally takes only 5 minutes to complete. ${ }^{21,22}$

All three Brief FAM-III Scales are scored using similar procedures: the assessment is made by a 4-point Likert scale $(1=$ strongly disagree, $4=$ strongly agree $)$; instructions for the respondent are provided at the top of the form. Responses are scored as $0,1,2$, or 3; the sum of these scores determines the total score, which can then be converted to a T-score or a percentile-score; T-scores have a mean or average of 50 and a standard deviation (SD) of 10. T-scores higher than 50 indicate more-than-average family difficulties, and T-scores lower than 50 indicate less-than-average family difficulties.

Two methods of administration are available; in the first method, family members indicate their responses on the Multi-Health System QuikScore Form, which is self-contained and includes all the materials to administer, the score, and the profile. The second method is the administration with the use of computer software program designed for Windows operating systems. ${ }^{22}$

The $\alpha$ coefficients for the Brief FAM-III in a nonclinical American sample show that all values were higher than 0.80 , indicating good internal consistency; in particular, this study, conducted on a group of 72 nonclinical subjects, reports the following estimates of each scale: 0.89 for Brief General, 0.80 for Brief Self-Rating, and 0.90 for Brief Dyadic Relationships. ${ }^{22}$ Similarly, a study conducted with a nonclinical sample, formed by Mexican Americans adults, found a moderate level of internal consistency $(\alpha=0.74){ }^{30}$

The FAD, ${ }^{24}$ in the Italian version of Grandi et al, ${ }^{31}$ measures structural, organizational, and transactional characteristics of families. It consists of six scales that assess the six dimensions of the McMaster's Model of Family Functioning - Affective Involvement, Affective Responsiveness, Behavioral Control, Communication, Problem Solving, and Roles, as well as a 7 th scale measuring general family functioning. The measure is comprised of 60 statements about a family; respondents (typically, all family members ages 12+) are asked to rate how well each statement describes their own family. All the FAD Scales are scored using similar procedures: the assessment is made by a 4-point Likert scale ( $1=$ strongly disagree, $4=$ strongly agree); the compilation of instrument takes approximately 15-20 to complete.

The FAD has been widely used in both research and clinical practice. Uses include screening to identify families experiencing problems, identifying specific domains in which families are experiencing problems, and assessing change following treatment.

The $\alpha$ coefficients for the Italian version show that the highest level of reliability is recorded in the General Operation scale (0.88), followed by: Affective Response (0.86), Problem Solving (0.78), Communication (0.77), Affective Involvement (0.73), Behavioral Control (0.59), and Roles (0.45). ${ }^{31}$

\section{Sample and procedure}

The research project involved 484 subjects, members of 162 Italian families. Participants were divided into:

1. Fathers $(n=162)$ aged between 35 and 73 years $(M=52.07$, $\mathrm{SD}=6.62)$;

2. Mothers $(n=162)$ aged between 34 and 69 years $(M=48.78$, $\mathrm{SD}=6.10)$;

3. Children $(n=160)$ aged between 12 and 35 years $(M=20.28$, $\mathrm{SD}=4.74)$.

The original version of the Brief FAM-III was translated into Italian, and the cross-cultural adaptation was completed accordingly. The data collection phase was started 
immediately after the translation of the Brief FAM-III and lasted about 6 months.

The sample was obtained with a snowballing sampling design. Participants were recruited among students at "Kore" University of Enna, and they were asked to help identify other subjects. This method uses a small pool of initial informants to nominate, through their social networks, other participants who could potentially contribute to the study and who met the eligibility criteria: in particular, only intact families were considered in the study, ie, those married (98\%) or in a common-law marriage (2\%).

Participation was secured through an informed consent procedure, which required that they provided active consent; the participation was completely voluntary; respondents were not paid for their participation and could withdraw their participation in the study at any time. The questionnaires were sent by e-mail to the students, and they completed them with their family; through e-mail, the participants were informed of the research aims and that the average time to complete questionnaires was 40 minutes for each family member; furthermore, participants were asked to complete consecutively all self-report measures and to answer to the questionnaires alone in order not to be influenced by other member's answers. They also provided information on their age, gender, and ethnicity prior to completing questionnaires.

For the purposes of the present research, 516 consent forms were distributed, $93.8 \%$ of which were returned with agreement to participate in the project; the large number of participants was designed to ensure the representativeness of the sample and to ensure that there were no significant differences between participants and nonparticipants.

The data collection lasted about 6 months, although the research project lasted for 1 year (2015 to 2016).

The Internal Review Board (IRB) of Faculty of Human and Social Sciences at the "Kore" University of Enna approved the present research.

\section{Data analysis}

Statistical Package for the Social Sciences (SPSS) for Windows version 23.0 (IBM, Armonk, NY, USA) was used.

In reference to the preliminary data, descriptive statistic was used to measure mean scores, $\mathrm{SD}$, and the $95 \%$ confidence interval obtained from the parents and children upon the administration of the Brief FAM-III. Pearson's correlation was carried out to measure the possible correlation between all Brief FAM-III Scales, which were administrated to the father, mother, and children. Furthermore, paired-sample $t$-test was used to test differences in mean of the father's Self-Evaluation versus the mother's Self-Evaluation, Dyadic (husband versus wife) versus Dyadic (wife versus husband), and the father's General versus the mother's General Scales.

Cronbach's $\alpha$ coefficients were estimated to measure indices of reliability for General, Dyadic, and Relationships Scales.

The reliability of the Brief FAM-III was also assessed using the split-half method, and the Guttman split-half correlation was calculated for the three scales; the split-half test is a classical psychometric method for evaluating reliability and is still used in the development of novel tests or during their adaptation to different languages. ${ }^{32,33}$

The correlation analysis was carried out to measure the concurrent validity, which was calculated only on the Brief General Scale, comparing it to General Scale of the FDA.

\section{Results}

Table 1 shows mean scores, SD, and confidence intervals obtained from the parents and children through the administration of the Self-Evaluation, Dyadic Relationships, and General Scales of the Brief FAM-III.

Table 2 shows the correlation between all Brief FAMIII Scales administrated to the father, mother, and children $(p<0.01$ in all cases). Particularly, results show the highest correlation between father and mother in the Self-Evaluation $(r=0.63)$, Dyadic ( $r=0.73)$, and General Scales $(r=0.73)$.

Furthermore, the analysis shows that the correlations between the three Brief FAM-III Scales in the Italian context are more highly correlated than those manifested from the normative sample. In particular, in the normative sample, in reference to the intercorrelations between General and Dyadic Scales, adults show a correlation equal to $r=0.73$, and children $r=0.65(p<0.01)$; in reference to the General/ Self intercorrelations, the value for adults is $r=0.72$ and for children is $r=0.71(p<0.01)$; and finally, in the Self/Dyadic

Table I Mean and standard deviation of Brief FAM-III Scales

\begin{tabular}{lllll}
\hline Scales & N & $\begin{array}{l}\text { Scale } \\
\text { range }\end{array}$ & M(SD) & $\mathbf{9 5 \% ~ C l}$ \\
\hline Father's Self-Evaluation & 162 & $0-42$ & $12.89(4.8 I)$ & $12.14-13.16$ \\
Mother's Self-Evaluation & 162 & $0-42$ & $12.28(5.26)$ & $11.46-13.10$ \\
Child's Self-Evaluation & 160 & $0-42$ & $13.74(5.24)$ & $11.92-14.56$ \\
Dyadic (husband versus wife) & 162 & $0-42$ & $11.83(6.16)$ & $10.87-12.79$ \\
Dyadic (wife versus husband) & 162 & $0-42$ & $12.47(6.28)$ & $11.50-13.44$ \\
Dyadic (father versus child) & 160 & $0-42$ & $13.29(5.38)$ & $12,45-14.13$ \\
Dyadic (mother versus child) & 160 & $0-42$ & $12.53(5.95)$ & $11.60-13.46$ \\
Dyadic (child versus mother) & 160 & $0-42$ & $10.92(5.56)$ & $10.05-11.79$ \\
Dyadic (child versus father) & 160 & $0-42$ & $11.75(6.06)$ & $10.80-12.70$ \\
Father's General & 162 & $0-42$ & $12.72(5.03)$ & $11.94-13.50$ \\
Mother's General & 162 & $0-42$ & $12.19(5.34)$ & $11,36-13.02$ \\
Child's General & 160 & $0-42$ & $13.30(5.9)$ & $13.38-14.22$ \\
\hline Abbreviations Bis
\end{tabular}

Abbreviations: Brief FAM-III, Family Assessment Measure Third Edition - Short Version; $\mathrm{Cl}$, confidence interval; $\mathrm{M}$, mean; SD, standard deviation. 
Table 2 Pearson's correlation for scores of all Brief FAM-III Scales

\begin{tabular}{|c|c|c|c|c|c|c|c|c|c|c|c|}
\hline Measures & $\mathbf{a}$ & b & c & d & e & $\mathbf{f}$ & $\mathbf{g}$ & $\mathbf{h}$ & $\mathbf{i}$ & j & $\mathbf{k}$ \\
\hline a. Father's Self-Evaluation & - & & & & & & & & & & \\
\hline b. Mother's Self-Evaluation & $0.63^{* *}$ & - & & & & & & & & & \\
\hline c. Child's Self-Evaluation & $0.60 * *$ & $0.56 * *$ & - & & & & & & & & \\
\hline d. Dyadic (husband versus wife) & $0.55^{* *}$ & $0.53 * *$ & $0.36 * *$ & - & & & & & & & \\
\hline e. Dyadic (wife versus husband) & $0.55^{* *}$ & $0.59 * *$ & $0.52 * *$ & $0.73 * *$ & - & & & & & & \\
\hline f. Dyadic (father versus child) & $0.48 * *$ & $0.46 * *$ & $0.5 I^{* *}$ & $0.36^{* *}$ & $0.45^{* *}$ & - & & & & & \\
\hline g. Dyadic (mother versus child) & $0.38 * *$ & $0.57 * *$ & $0.38 * *$ & $0.42^{* *}$ & $0.56 * *$ & $0.62 * *$ & - & & & & \\
\hline h. Dyadic (child versus mother) & $0.36 * *$ & $0.37 * *$ & $0.44 * *$ & $0.42^{* *}$ & $0.4 I^{* *}$ & $0.4 I^{* *}$ & $0.48 * *$ & - & & & \\
\hline i. Dyadic (child versus father) & $0.47^{* *}$ & $0.43 * *$ & $0.59 * *$ & $0.45^{* *}$ & $0.43^{* *}$ & $0.49 * *$ & $0.44 * *$ & $0.62 * *$ & - & & \\
\hline j. Father's General & $0.55^{* *}$ & $0.66 * *$ & $0.48 * *$ & $0.55^{* *}$ & $0.6 I^{* *}$ & $0.44 * *$ & $0.49 * *$ & $0.32 * *$ & $0.48 * *$ & - & \\
\hline k. Mother's General & $0.52^{* *}$ & $0.44^{* *}$ & $0.61 * *$ & $0.40 * *$ & $0.48 * *$ & $0.40 * *$ & $0.39 * *$ & $0.65 * *$ & $0.66 * *$ & $0.73 * *$ & - \\
\hline I. Child's General & $0.65 * *$ & $0.55^{* *}$ & $0.52 * *$ & $0.5 I^{* *}$ & $0.56 * *$ & $0.49 * *$ & $0.37 * *$ & $0.37 * *$ & $0.39 * *$ & $0.60 * *$ & $0.60 * *$ \\
\hline
\end{tabular}

Note: ${ }^{* *} p<0.01$, two-tailed.

Abbreviation: Brief FAM-III, Family Assessment Measure Third Edition - Short Version.

intercorrelations, adults show a correlation equal to $r=0.53$, and for children $r=0.62(p<0.01)$. Similarly, in the Italian sample, in the General/Dyadic intercorrelations, the father's score was equivalent to $r=0.55$, the mother's $r=0.48$, the children's scores $r=0.37$ (versus mother) and $r=0.39$ (versus father). In reference to the General/Self intercorrelations, the values are the following: the father's score $r=0.55$, the mother's score $r=0.44$, and the children's score $r=0.52$. Finally, in the Self/Dyadic intercorrelations, the value for father's score is $r=0.55$, for the mother's $r=0.59$, the children's $r=0.44$ (versus mother) and $r=0.59$ (versus father). ${ }^{22}$

Finally, the paired-sample $t$-test shows a significant difference between the father's Self-Evaluation and the mother's Self-Evaluation $\left(\mathrm{t}_{(1,161)}=2.039, p=0.04\right)$, demonstrating a better self-perception of fathers compared to mothers (Table 3 ).

\section{Reliability of the Brief FAM-III}

General item analysis shows good indices of reliability with Cronbach's $\alpha$ coefficients equal to 0.96 .

Cronbach's $\alpha$ coefficients show the following results: $\alpha=0.88$ for the Self-Rating Scale, $\alpha=0.94$ for the Dyadic Relationships Scale, and $\alpha=0.90$ for the General Scale. These results are a little higher than those manifested from the normative sample, in which the $\alpha$ coefficients present values higher than 0.80 , reporting the following estimates: 0.89 for the Brief General, 0.80 for the Brief Self-Rating, and 0.90 for the Brief Dyadic Relationships Scales. ${ }^{22}$

Moreover, by splitting the family members, the overall FAM rating presents substantial $\alpha$ coefficients (Table 4 ).

\section{Split-half reliability}

The reliability of the Brief FAM-III was also assessed using the split-half method, and the Guttman split-half correlation
Table 3 Paired-sample $t$-test in reference to the Brief FAM-III Scales (father versus mother)

\begin{tabular}{llll}
\hline Measures & $\mathbf{T}$ & $\mathbf{d f}$ & $\boldsymbol{p}$ \\
\hline Father's Self-Evaluation versus Mother's Self-Evaluation & 2.04 & 16 & 0.04 \\
$\begin{array}{l}\text { Dyadic (husband versus wife) versus Dyadic } \\
\text { (wife versus husband) }\end{array}$ & 1.77 & 16 & 0.08 \\
Father's General versus Mother's General & 1.74 & 16 & 0.08 \\
\hline
\end{tabular}

Abbreviation: Brief FAM-III, Family Assessment Measure Third Edition - Short Version; $d f$, degrees of freedom.

Table 4 Reliability of the Brief FAM-III Scales for each family member

\begin{tabular}{llll}
\hline Scales & Father & Mother & Child \\
\hline Self-rating & 0.70 & 0.75 & 0.74 \\
Dyadic relationships & 0.85 & 0.88 & 0.88 \\
& 0.84 (husband & 0.84 (wife versus & 0.84 (child \\
& versus wife) & husband) & versus father) \\
& 0.78 (father & 0.81 (mother & 0.79 (child \\
& versus child) & versus child) & versus mother) \\
General & 0.76 & 0.74 & 0.79 \\
\hline
\end{tabular}

Abbreviation: Brief FAM-III, Family Assessment Measure Third Edition - Short Version.

was calculated for the three scales. The reliability of the SelfRating Scale was equal to 0.76, the Dyadic Relationships Scale was 0.86 , and the General Scale was 0.86 .

Furthermore, Table 5 shows the Guttman split-half correlation for each family member.

\section{Concurrent validity}

Concurrent validity is calculated comparing the Brief FAM-III General Scale to the FAD General Scale (Table 6): the correlation analysis shows that the General Scales are positively and significantly correlated each other $(p<0.01)$. 
Table 5 Split-half reliability of the Brief FAM-III Scales for each family member

\begin{tabular}{llll}
\hline Measures & Father & Mother & Child \\
\hline Self-rating & 0.70 & 0.68 & 0.65 \\
Dyadic relationships & $0.8 \mathrm{I}$ & 0.83 & 0.86 \\
& 0.80 (husband & 0.80 (wife versus & 0.87 (child \\
& versus wife) & husband) & versus father) \\
& 0.80 (father & 0.82 (mother & 0.74 (child \\
& versus child) & versus child) & versus mother) \\
General & 0.76 & 0.76 & 0.84 \\
\hline
\end{tabular}

Abbreviation: Brief FAM-III, Family Assessment Measure Third Edition - Short Version.

Table 6 Correlation analysis between the Brief FAM-III General Scale and the FAD General Scale

\begin{tabular}{llllll}
\hline Measures & a. & b. & c. & d. & e. \\
\hline a. Father's General Brief FAM & - & & & & \\
b. Father's General FAD & $0.5 I^{* *}$ & - & & & \\
c. Mother's General Brief FAM & $0.73^{* *}$ & $0.38^{* *}$ & - & & \\
d. Mother's General FAD & $0.35^{* *}$ & $0.62^{* *}$ & $0.32^{* *}$ & - & \\
e. Child's General Brief FAM & $0.60^{* *}$ & $0.54^{* *}$ & $0.59^{* *}$ & $0.38^{* *}$ & - \\
f. Child's General FAD & $0.31^{* *}$ & $0.68^{* *}$ & $0.36^{* *}$ & $0.61^{* *}$ & $0.67^{* *}$ \\
\hline
\end{tabular}

Note: $* * p<0.01$, two-tailed.

Abbreviations: Brief FAM-III, Family Assessment Measure Third Edition - Short Version; FAD, family assessment device.

\section{Discussion and conclusion}

The present study aimed to evaluate the psychometric properties of the Italian version of the Family Assessment Measure Third Edition - Short Version. The findings indicate that the Brief FAM-III is a reliable, valid measure of family functioning in a nonclinical Italian sample. In fact, it can be used for the purposes of preliminary screening and to obtain a basis idea as to whether there are problems in family functioning, which may determine an inaccurate and dysfunctional perception of the nucleus, in different moments of the family life cycle.

Although it is one of the most widely used family assessment tools, it has never been translated into Italian, and the research supporting its use in the Italian context is insufficient. Few studies have used the Brief Family Assessment Measure to value family functioning in a nonclinical sample. One of these is the study of Bloomquist and Harris, ${ }^{34}$ who administered only the Brief FAM General Scale to 110 undergraduates aged between 17 and 43; this study showed that the mean scores are slightly higher than those obtained from the normative sample on which the FAM quick scores are based. By contrast, only one study of validation was made in a non-English speaking context. In Marin and Huber's study, ${ }^{30}$ by using the Brief General Scale in a group of Spanish adults, a moderate level of internal consistency was demonstrated.

Since Italy and Spain can be considered more similar to each other than the American context, the present study was expected to find similar results to the Spanish research. In fact, from a psychological and sociological point of view, Italy and Spain represent two areas divided by two clearly differentiated major regions: a northern region, where nuclear, conjugal, or restricted family structures are more frequent; and a southern region, where extended, parental, or enlarged families are predominant.

In reference to the psychometric results, this paper has explored the use of all three scales of Brief FAM-III with a large sample of Italian families, comparing the current data with the American normative data.

The first data analysis showed that the intercorrelations between the three Brief FAM Scales (for fathers, mothers, and children) in the Italian context are more highly correlated than those manifested from the normative sample; however, this is appropriate because the three scales measure overall family functioning from different perspectives. Furthermore, in the Italian version of the Brief FAM-III, the analysis showed a significant difference between the father's Self-Evaluation and the mother's Self-Evaluation, demonstrating a better self-perception of fathers compared to mothers. This finding could be explained by the fact that in the Italian culture, roles within the family are much emphasized: in fact, the Italian mothers typically spend more time with their children than father. In addition, the literature underlines that children report higher disclosure with mothers than with fathers, and this element may influence the father's self-perception. ${ }^{8,35}$

In accordance to previous studies on the original version of the Brief FAM-III, in the Italian version, the scales of the questionnaire also showed an appropriate degree of internal consistency and reliability. In particular, in reference to the internal consistency, the mean scores of all subscales are a little higher than those manifested from the normative sample, thus proving to be representative of the theoretical reference model that underpins it.

Finally, concerning the comparison between the BriefFAM General Scale and the FAD General Scale, positive and significant correlations were found, providing evidence that the Brief FAM-III is a good instrument to measure family functioning.

Generally, the present study provides support for the research objectives, although some limitations need to be better addressed by future research. First, the tools used for testing convergent validity were limited for Brief FAM-III, since, to the best of our knowledge, this was the first Italian study on Family Assessment Measure. Second, it should be noted that the Social Desiderability and Defensiveness subscales only appear on the General Scale.

Further studies will be needed to determine its usefulness for the Italian population in the clinical setting because literature has amply demonstrated the influence of family 
functioning on the presence of internalizing ${ }^{8,33,36}$ and externalizing symptoms, ${ }^{37}$ above all during adolescence. ${ }^{38,39}$ In fact, evidence indicates that with early intervention (such as counseling services, parenting skill enhancement) many individuals can be steered away from involvement in critical events, which may be costly to both individuals and communities. ${ }^{40,41}$

\section{Disclosure}

The authors declare that the present research has not had any commercial or financial relationships which could be represented as a potential conflict of interest. The authors report no other conflicts of interest in this work.

\section{References}

1. Malagoli Togliatti M, Catugno A. Psicodinamica delle relazioni familiari. [Psychodynamic of Family Relationships]. Bologna, Italy: Il Mulino; 1996. Italian.

2. Iacolino C, Pellerone M, Pace U, Ramaci T, Castorina V. Family functioning and disability: a study on Italian parents of disabled children. Eur Proc Soc Behav Sci. 2016;8:39-52.

3. Pellerone M, Passanisi A, Bellomo MFP. Identity development, intelligence structure, and interests: a cross-sectional study in a group of Italian adolescents during the decision-making process. Psychol Res Behav Manag. 2015;8:239-249.

4. McGoldrick M, Carter EA. The Family Life Cycle: A Framework for Family Therapy. New York, NY: Gardner Press; 1980.

5. Erikson EH. Psychological Issues: Identity and the Life Cycle. 1st ed. New York, NY: International University Press; 1959.

6. Magnano P, Ramaci T, Platania S. Self-efficacy in learning and scholastic success: implications for vocational guidance. Procedia Soc Behav Sci. 2014;116:1232-1236.

7. Pellerone M, Craparo G, Tornabuoni Y. Relationship between parenting and cognitive schemas in a group of male adult offenders. Front Psychol. 2016;7:302.

8. Pellerone M, Tolini G, Polopoli C. Parenting, identity development, internalizing symptoms and alcohol use. A cross-sectional study in a group of Italian adolescents. Neuropsychiatr Dis Treat. 2016;12:1769-1778.

9. Epstein N, Bishop D, Baldwin L. The McMaster Model of Family Functioning: a view of the normal family. In Walsh F, editor. Normal Family Processes. New York, NY: Guilford Press; 1982:125-141.

10. Tolan PH, Gorman-Smith D, Zelli A, Huesmann LR. Assessment of family relationship characteristics: a measure to explain risk for antisocial behavior and depression in youth. Psycholl Assess. 1997;9:212-223.

11. Beavers WR, Hampson RB, Hulgus YF. Beavers Systems Model Manual. Dallas, TX: Southwest Family Institute; 1990.

12. McFarlane AH, Bellissimo A, Norman GR. Family structure, family functioning and adolescent well-being: the transcendent influence of parental style. J Child Psychol Psych. 1995;36(5):847-864.

13. Blandini M, Fecarotta P, Buscemi B, et al. Anti-stress protocol based on the psychological functional model. Int J Educ Res. 2015;3(3):459-468.

14. Ramaci T, Pellerone M, Iacolino C. Stress-related diseases: significant influence on the quality of life at workplaces. Eur Proc Soc Behav Sci. 2016;8:29-38.

15. Dai L, Wang L. Review of family functioning. Open J Soc Sci. 2015;3:134-141.

16. Olson DH, Russell CS, Sprenkle DH. Circumplex model of marital and family systems. Theoretical update. Family Process. 1983;6(22):69-83.

17. Skinner HA. Toward the integration of classification theory and methods. J Abnorm Psychol. 1981;90:68-87.

18. Dishion TJ, Patterson GR, Stoolmiller M, Skinner ML. Family, school and behavioral antecedents to early adolescent involvement with antisocial peers. Develop Psychol. 1991;27(1):172-180.
19. Steinhauer PD, Santa-Barbara J, Skinner HA. The process model of family functioning. Can J Psychiatry. 1984:29(2):98-111.

20. Skinner HA, Steinhauer PD, Santa-Barbara J. The family assessment measure. Can J Psychiatry. 1983;2(2):91-105.

21. Skinner HA, Steinhauer PD, Sitarenios G. Family assessment measure (FAM) and process model of family functioning. J Fam Ther. 2000; 22:190-210

22. Skinner AH, Steinhauer PD, Santa-Barbara J. Family Assessment Measure Version III. Toronto, Canada: Multi-Health System; 1995.

23. Specchiale A, Attinà AN, De Maria G, et al. Pilot Study on the role of psychosocial aggression in a sample of cops and robbers. Acta Medica Mediterranea. 2013;29:407-410.

24. Epstein NB, Baldwin LM, Bishop DS. The Mc Master family assessment device. J Marital Fam Ther. 1983;9:171-180.

25. Moos RH. Family Environment Scales. Palo Alto, CA: Consulting Psychologists Press; 1981.

26. Bloom BL. A factor analysis of self-report measures of family functioning. Family Process. 1985;24(2):225-239.

27. Jacob $\mathrm{T}$. The role of the time in the assessment of family functioning. J Marital Fam Ther. 1995;21(3):281-286.

28. Delvecchio E, Di Riso D, Chessa D, Salcuni S, Mazzeschi C, Laghezza L. Expressed emotion, parental stress, and family dysfunction among parents of nonclinical Italian children. J Child Fam Stud. 2013; 10:826-833.

29. Laghezza L, Delvecchio E, Pazzagli C, Mazzeschi C. The Family Assessment Measure III (FAM III) in an Italian sample. An exploratory study. Boll Psicol Appl. 2014;269:17-28.

30. Marin MR, Huber CH. Mexican American Elderly: self-reported anxiety and the mediating influence of family protective factors. Fam J. 2010; 19:63-72.

31. Grandi S, Fabbri S, Scortichini S, Bolzani R. Validazione italiana del Family Assessment Device (FAD). [Italian validation of the Family Assesment Devise]. Bologna: Dipartimento di Psicologia, Università degli Studi di Bologna. Available from: http://www.rivistadipsichiatria. it/allegati/00275_2007_02/fulltext/05\%20114-122.pdf.

32. Pires T, Assis SG, Avanci JQ, Pesce RP. Cross-cultural adaptation of the General Functioning Scale of the family. Rev Saude Publica. 2016;50(32):1-10.

33. Park SJ, Kang KA. Development of a measurement instrument for parenting behavior of primary caregivers in early childhood. $J$ Korean Acad Nurs. 2015;45(5):650-660.

34. Bloomquist ML, Harris WG. Measuring family functioning with the MMPI: a reliability and concurrent validity study of three MMPI scales. J Clin Psychol. 1984;40:1209-1303.

35. Pellerone M, Iacolino C, Mannino G, Formica I, Zabbara SM. The influence of Parenting on Maladaptive Cognitive Schema: a cross-sectional research on a group of adults. Psychol Res Behav Manag. 2017;10:47-58.

36. Craparo G, Gori A, Mazzola E, Petruccelli I, Pellerone M, Rotondo G. Posttraumatic stress symptoms, dissociation, and alexithymia in an Italian sample of flood victims. Neuropsychiatr Dis Treat. 2014;10:2281-2284.

37. Beyers JM, Bates JE, Pettit GS, Dodge KA. Neighborhood structure, parenting processes, and the development of youths' externalizing behaviors: a multilevel analysis. Am J Community Psychol. 2003;31:35-53.

38. Pellerone M, Tomasello G, Migliorisi S. Relationship between parenting, alexithymia and adult attachment styles: a cross-sectional study on a group of adolescents and young adults. Clin Neuropsychiatr. 2016;13:1-10.

39. Sommantico M, Donizzetti AR, De Rosa B, Parrello S, Osorio GM. L'invarianza per età nella validazione italiana dell'Aggression Questionnaire (AQ) di Buss e Perry. [The invariance by age in Italian validation of the Aggression Questionnaire (AQ) by Buss and Perry]. Psicologia della Salute. 2015;3:111-125. Italian.

40. Ozechowski TJ, Liddle HA. Family-based therapy for adolescent drug abuse: knowns and unknowns. Clin Child Fam Psychol Rev. 2000;3: 269-298.

41. Parrello S, Giacco N. Aggiungere vita ai giorni: la Distrofia muscolare di Duchenne nella narrazione delle madri. [Add life to days: Duchenne muscular dystrophy in the narrative of mothers]. Psicologia della Salute. 2014;1:113-124. Italian. 
Psychology Research and Behavior Management is an international, peerreviewed, open access journal focusing on the science of psychology and its application in behavior management to develop improved outcomes in the clinical, educational, sports and business arenas. Specific topics covered in the journal include: Neuroscience, memory and decision making; Behavior modification and management; Clinical applications; Business and sports performance management; Social and developmental studies; Animal studies. The manuscript management system is completely online and includes a very quick and fair peer-review system, which is all easy to use. Visit http://www. dovepress.com/testimonials.php to read real quotes from published authors.

Submit your manuscript here: https://www.dovepress.com/psychology-research-and-behavior-management-journal 